\title{
In-flight Spatial Disorientation Induces Roll Reversal Errors when Using the Attitude Indicator
}

\begin{abstract}
We hypothesized that an incorrect expectation due to spatial disorientation may induce roll reversal errors. To test this, an in-flight experiment was performed, in which forty non-pilots rolled wings level after receiving motion cues. A No-leans condition (subthreshold motion to a bank angle) was included, as well as a Leansopposite condition (leans cues, opposite to the bank angle) and a Leans-level condition (leans cues, but level flight).

The presence of leans cues led to an increase of the roll reversal error (RRE) rate by a factor of 2.6. There was no significant difference between the Leans-opposite and Leans-level condition. This suggests that the expectation strongly affects the occurrence of an RRE, and that people tend to base their responses on motion cues instead of on information on the AI.

We conclude that expectation and spatial disorientation have a large effect on piloting errors and may cause hazardous aircraft upsets.
\end{abstract}

Keywords: Aviation, Displays, Spatial disorientation, Surprise, Upset recovery

\section{Introduction}

In previous research, pilots were found to sometimes make 'roll reversal errors' (RREs) when referencing the attitude indicator (AI), which is also known as the artificial horizon (Beringer, Williges \& Roscoe, 1975; Hasbrook \& Rasmussen, 1973; Müller et al., 2018; Singer \& Dekker, 2002). These RREs, which are roll inputs towards the opposite of the required side, are thought to be facilitated by an ambiguity of the presented bank angle on the generally used moving-horizon type AI (see, Figure 1; Roscoe, 2004; Previc \& Ercoline, 1999; Wickens, 2003). This ambiguity may cause interpretation errors known as 'horizon control reversals', in which case the aircraft symbol and the horizon symbol are being confused (Johnson \& Roscoe, 1972). The AI in Figure 1, for instance, would then be incorrectly interpreted as indicating a bank to the left instead of to the right. Previous simulator-based and in-flight studies showed that pilots (1.5-3\% RREs) as well as non-pilots (ca. 20\% RREs) are susceptible to RREs when they suddenly had to respond to a AI that was shown (Bauerschmidt \& Roscoe 1960; Beringer, Williges, Roscoe, 1975; Hasbrook \& Rasmussen, 1973; Ince, Williges, Roscoe, 1975; Muller et al., 2018; Roscoe \& Williges, 1975; Singer \& Dekker, 2008). However, these studies did not account for the potential presence of an incorrect expectation with regard to the bank angle when viewing the AI.

Units and symbols: $\mathrm{s}=$ seconds, $\mathrm{Hz}=\mathrm{Hertz},{ }^{\circ}=\operatorname{arc}$ degrees, $S D=$ standard deviation 


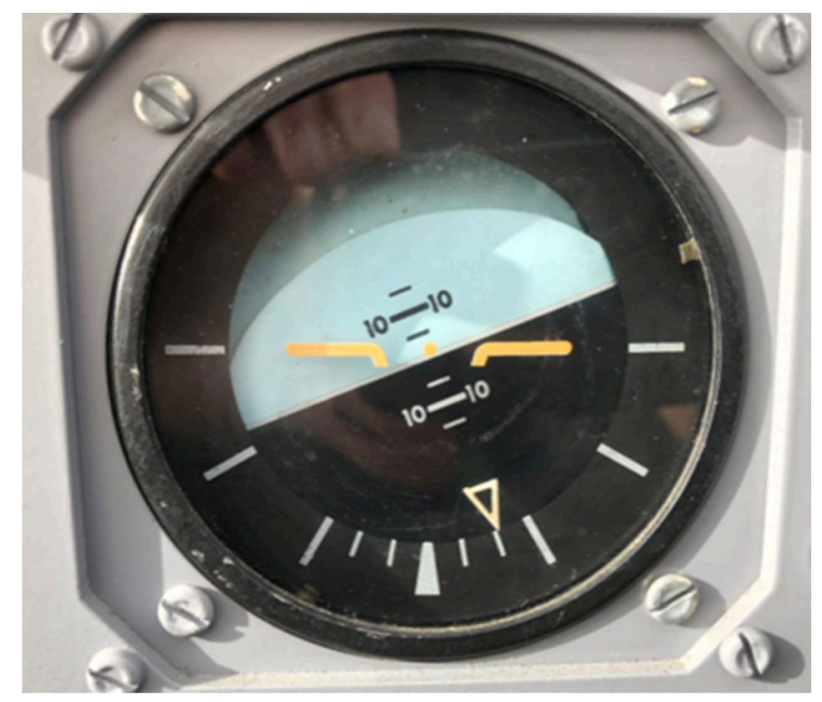

Figure 1. An example of a moving-horizon type AI, as used in this study, displaying a bank to the right.

Insight into the effect of expectation on RREs is because incorrect expectations may arise in flight due to spatial disorientation. Spatial disorientation involves an erroneous sense of the aircraft attitude and motion relative to the earth, which is caused by misleading vestibular and other motion cues (Gillingham, 1992). It occurs most often in poor visibility conditions, when reading the instruments correctly is most crucial. Spatial disorientation continues to be a serious safety risk, as it was estimated to have contributed to $12 \%$ of loss of control accidents in transport and commuter aircraft, and $24 \%$ of fatalities between 1996 and 2010 (Belcastro et al., 2017). The most prevalent form of spatial disorientation in aviation is the 'leans' illusion (Holmes et al., 2003; Navanthe \& Singh, 1994). This is caused by the vestibular system being insensitive to low roll accelerations, leading to an incorrect sensation of the bank angle. The leans has been a suspected factor in, for example, the accident of Flash Airlines flight 604 (Bureau d'Enquêtes et d'Analyses pour la Sécurité de l'Aviation Civile [BEA], 2009), which occurred shortly following takeoff at night. The first officer alerted the captain of the gradual, unintended turn from left to right, upon which the captain expressed surprise. The captain (pilot flying) followed with a roll input that caused an increase in the bank angle, which led to an overbank and loss of control. Other accidents where leans was suspected to have caused an RRE were Kenya Airways flight 5Y-KYA (Cameroon Civil Aviation Authority, 2010) and Crossair flight 498 (Aircraft Accident Investigation Bureau, 2002).

It can be hypothesized that misinterpretations and RREs are more likely to occur when the controller has an incorrect expectation about the bank angle due to the leans. Expectation is an important factor in the interpretation of ambiguous information (Maloney \& Zhang, 2010). In the current in-flight experiment, we investigate if there is an effect of expectation, induced by leans cues, on the occurrence of RREs. Several test conditions will be included to investigate if the expectation causes misinterpretations of the AI. 


\section{Material and methods}

\subsection{Participants}

Forty non-pilot participants were invited from the Aerospace Engineering faculty of Cranfield University (34 men, 6 women, mean age $=25.1$ years, $S D=3.7$ ). Participants reported no vestibular issues, had (corrected to) normal vision, and reported being well rested. Twenty-three participants had previously controlled an aircraft on one or two occasions, while one was in flight training (ca. 20 hours). Participants rated their simulated flying experience on average at 1.93 points, median $=1, S D=1.29$, on a 1-5 points Likert-type scale ranging from 'none or very little' (1) to 'very much' (5). The experiment was approved by the research ethics review board of the university and participants provided informed consent prior to participating.

\subsection{Apparatus}

The experiment took place in a light propeller aircraft (Scottish Aviation Bulldog 122). Participants used a centerstick and had the AI (Figure 1) available in front of them (see, Figure 2). Test runs prior to the experiment confirmed that when looking at the AI, it would be very difficult to notice that the outside horizon has an angle of $10^{\circ}$. This is because the outside view is relatively bright compared to the instrument panel, which would require adjusting the eyes. Also, the front view is largely obstructed by the instrument panel.

Roll rate of the aircraft was logged at $100 \mathrm{~Hz}$ using an inertial measurement unit (IMU; Shimmersensing, Dublin, $500^{\circ} / \mathrm{s}$ setting) attached to the top of the instrument panel in front of the participant. Roll rates were corrected by subtracting the mean roll rate of the whole flight. The stick inputs were filmed using a Gopro ${ }^{\mathrm{TM}}$ camera, placed above and behind the seats, facing the participant's center stick and the instrument panel (See Figure 2 for a screenshot).

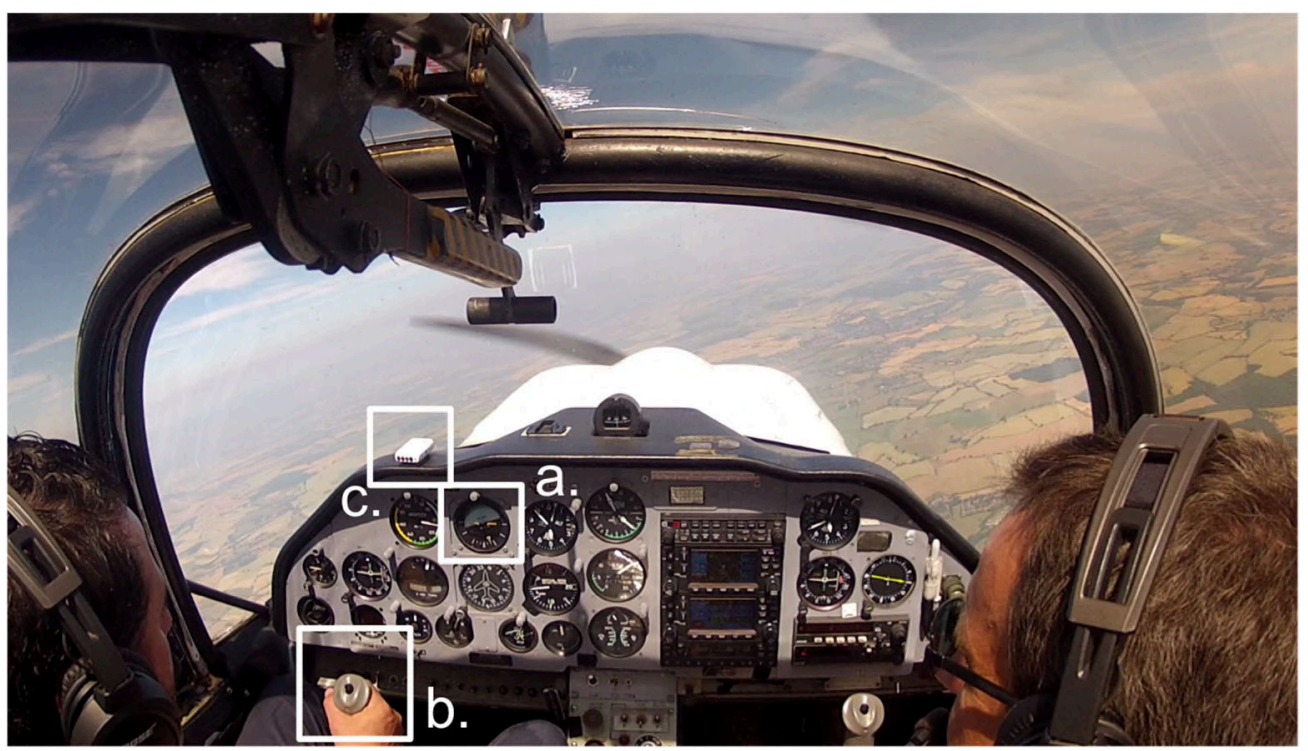


Figure 2. A screenshot of the video recording. Left is the participant with the AI (a) the centerstick (b) and the IMU (c) visible, right is the experimenter pilot.

2.3 Procedure and test conditions

After filling in a questionnaire and receiving a briefing, the participant was seated in the left hand seat of the aircraft and the experimenter pilot flew to the test area. The participant was then familiarized with the controls for approximately three minutes by flying left and right turns and leveling the aircraft from bank angles using the AI. Then, the participant performed a number of test conditions, with one run per condition. This run started with the participant putting on a blindfold. The pilot then flew a maneuver to induce a specific motion cue (see below). Immediately after, the participant was asked to take the stick with their dominant hand and, after a countdown from three, remove the blindfold and roll the wings level using the AI. The runs took place at an altitude with minimal turbulence and with the sun from behind. Tests were planned on days when the pilot judged the weather calm enough for minimal turbulence.

The maneuvers flown in each condition are listed in Figure 3. First, a number of practice runs (at least four, mean $=4.7, S D=1.08$ ) was flown until the pilot considered the participant's performance to be adequate. In the practice runs, the cues were aimed to set up an expectation that matched the AI (the Matching condition). For the analysis of performance in this condition, the results of the third and fourth practice run were used. More practice runs were performed if the pilot deemed performance inadequate. The practice session ended with a run in which the pilot waited $30 \mathrm{~s}$ before presenting the motion cue, to make this matching run similar to the subsequent test runs.

Three test runs followed, one for each test condition (No-leans, Leansopposite and Leans-level, see Figure 3). In the No-leans condition, the aircraft was rolled to $10^{\circ}$ bank slowly (at circa $0.3^{\circ} / \mathrm{s}$ and $.01 \mathrm{~Hz}$, which is below the $4.0^{\circ} / \mathrm{s}$ perception threshold; Gundry, 1978), while flying in a coordinated turn. The intended expectation here was no bank. In the Leans-opposite condition, the aircraft was rolled similarly slowly to $20^{\circ}$ bank, and then quickly back (at circa 5.0 $\% / \mathrm{s}$ and $.25 \mathrm{~Hz}$ ) to $10^{\circ}$ bank on the same side. The intended expectation here was a bank angle opposite to the actual bank angle. In the Leans-level condition, the aircraft was rolled slowly to $20^{\circ}$ bank, and then quickly back to level. The intended expectation here was a bank angle, whereas the AI showed level flight. The direction of the fast roll in the test conditions was always the same within each participant, and it was counterbalanced between participants. Two variations of condition sequence were used. The first half of participants followed sequence $A$ (1-2-3-4) and the second half sequence B (1-4-3-2). The numbers here indicate the conditions as numbered in Figure 3. 


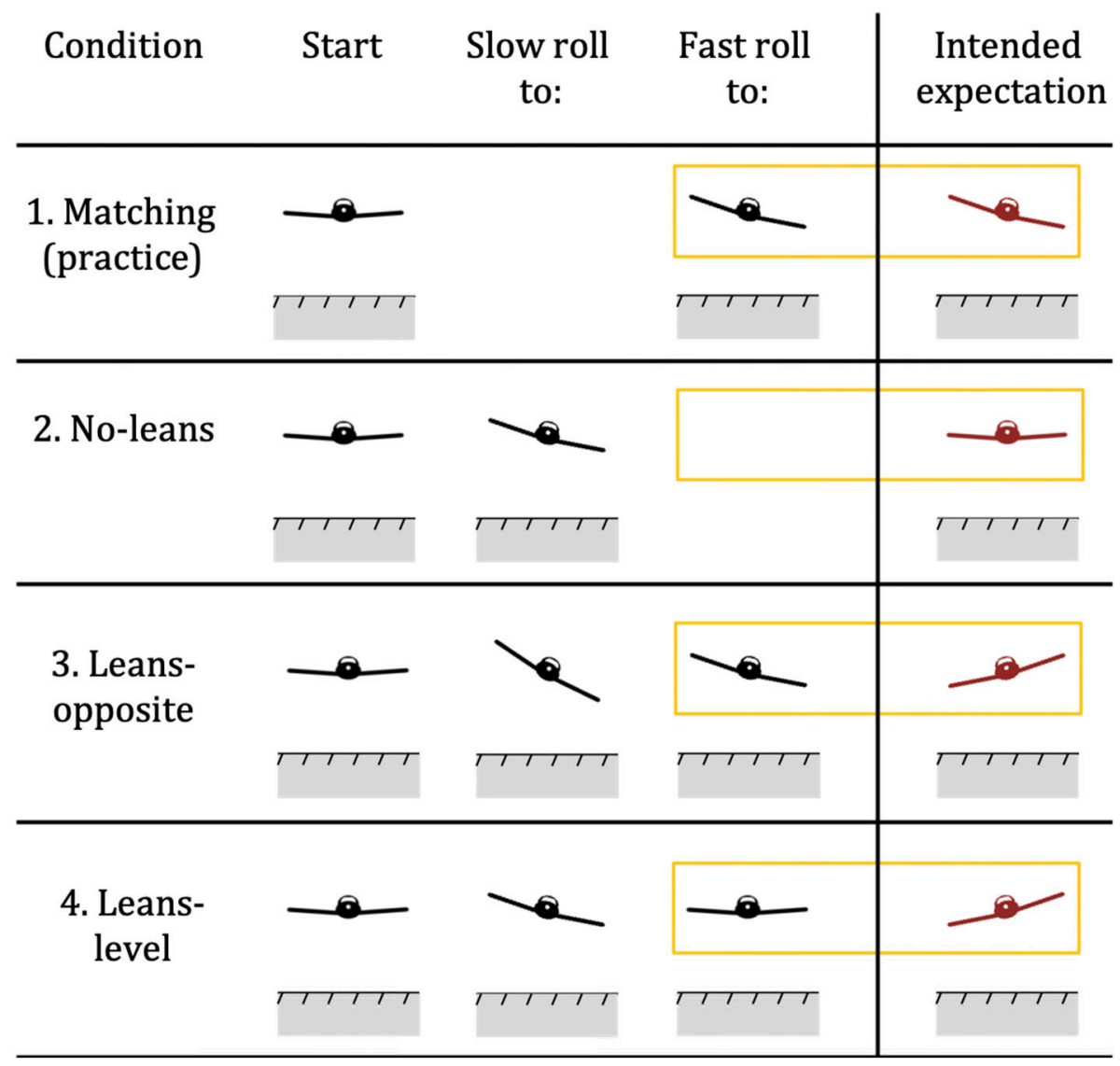

Figure 3. The practice and test conditions, with the flown maneuvers and the intended expectation (right).

\subsection{Dependent measures}

\subsubsection{Error rate}

The experimenter pilot observed the participant's first roll input and registered its direction on a log sheet. An error was registered if the first input caused the aircraft to roll away from level. This error would be an RRE in the Matching, Noleans or Leans-opposite condition, and an undesired input (not an RRE) in the Leans-level condition. The data on the log sheet were checked post-flight by an experimenter using video data, or, if video was not available, with IMU data. The agreement between both observations was high (98.1\%). In case of disagreement the video analysis took precedence.

\subsubsection{Error duration}

Video analysis was used to determine the start of the participant's first input, and the moment the participant started to move the stick back in the opposite direction again. The time between these moments was defined as the duration of an error. This definition was chosen instead of, for instance, the time until reaching level flight, to decrease potential variance due to inter-personal differences in control input strength. 


\subsubsection{Reaction time}

The reaction time was defined as the time from removal of the blindfold until the start of the first input. These were both measured with video analysis. This was reported separately for correct and incorrect inputs.

\subsubsection{Learning effect}

To check whether there was a training or surprise effect on the occurrence of errors, the predictive effect of the sequence (A or B, Figure 3 ) on the occurrence of an error and the error duration was determined. If participants learned to anticipate the mismatching AI presentations, they may perform better in later runs.

\subsubsection{Subjective measures}

Participants who performed the No-leans condition last $(n=20)$ provided verbal feedback of their sensation of the bank angle (left, right or none) before the pilot started the countdown for the response. This was not done for participants performing the No-leans condition first, so as not to make them conscious of the goal of the experiment.

\subsubsection{Run similarity check}

We measured two parameters to test if the runs in each condition were similarly set up. The duration participants were blindfolded was measured. The duration of the fast roll cue in the Leans-opposite and Leans-level condition was defined as the time the roll rate exceeded $1.0^{\circ} / \mathrm{s}$ (as measured with the IMU).

\subsection{Hypotheses}

We expected error rates in our No-leans condition to be similar to previous inflight studies with non-pilot participants (i.e., around 20\%). Error rates in the mismatching conditions (Leans-opposite and Leans-level) were expected to be higher than in the No-leans condition, as the misleading motion cues are expected to cause additional errors. Since the Leans-opposite condition allows for additional interpretation errors (horizon control reversals), most errors were expected in the Leans-opposite condition.

Concerning error duration, we expected that interpretation errors take longer to overcome than merely incorrect initial inputs. Therefore, the error durations were expected to be shorter in the Leans-level condition than in the Leans-opposite and No-leans conditions.

Concerning reaction times, the reaction times in RREs were expected to be shorter than those of correct inputs, because really looking before responding would likely lead to preventing an RRE. However, in the No-leans conditions, participants would be more likely to look longer at the AI in any case, because there should be no motion cues here to prompt a response. 


\subsection{Data analysis}

Results of the Matching condition (practice) are reported, but they are not used for any comparisons with the test conditions. The error rates in the three test conditions were analyzed using Chochran's Q for main effects. Post-hoc comparisons between all conditions were performed using McNemar with HolmBonferroni correction. The effects of Condition on error duration as well as reaction time was tested using repeated-measures ANOVAs and post-hoc pairwise t-tests with Holm-Bonferroni correction. The reaction times between errors and correct responses were compared for the Leans-opposite and No-leans conditions separately, using independent-samples t-tests, while correcting for two comparisons using Holm-Bonferroni.

Furthermore, training effects were tested by performing a binary logistic regression, with the sequence of conditions (A and B; see Figure 3) as predictor, and occurrence of an error (true or false) as dependent measure. The run characteristics were compared between each pair of conditions with pairedsamples t-tests without correction to check for differences.

\section{Results}

\subsection{Performance examples}

Figure 4 (top) shows an example of an RRE in the Leans-opposite condition. At $t=$ $-4 \mathrm{~s}$, the pilot induced a motion cue by rolling the aircraft from a 20 to a $10^{\circ}$ bank angle with a maximum roll rate of about $13^{\circ} / \mathrm{s}$. Removal of the blindfold occurred at $\mathrm{t}=0$. After removing the blindfold, the participant responded by rolling into the opposite direction, i.e., away from level, for about $2 \mathrm{~s}$, before correcting the input towards the correct direction.

Figure 4 (bottom) shows a different example of an RRE in the Leansopposite condition. A video recording of this event can be found in the supplementary files in Appendix A. In this case, the participant made two extra RREs at $\mathrm{t}=2.5$ and $4 \mathrm{~s}$, before rolling to level flight. The confusion in this example lasted for a total of almost five s. However, the first input briefly stopped at around $t=1.8 \mathrm{~s}$, meaning that the measured error duration was only $0.8 \mathrm{~s}$. 

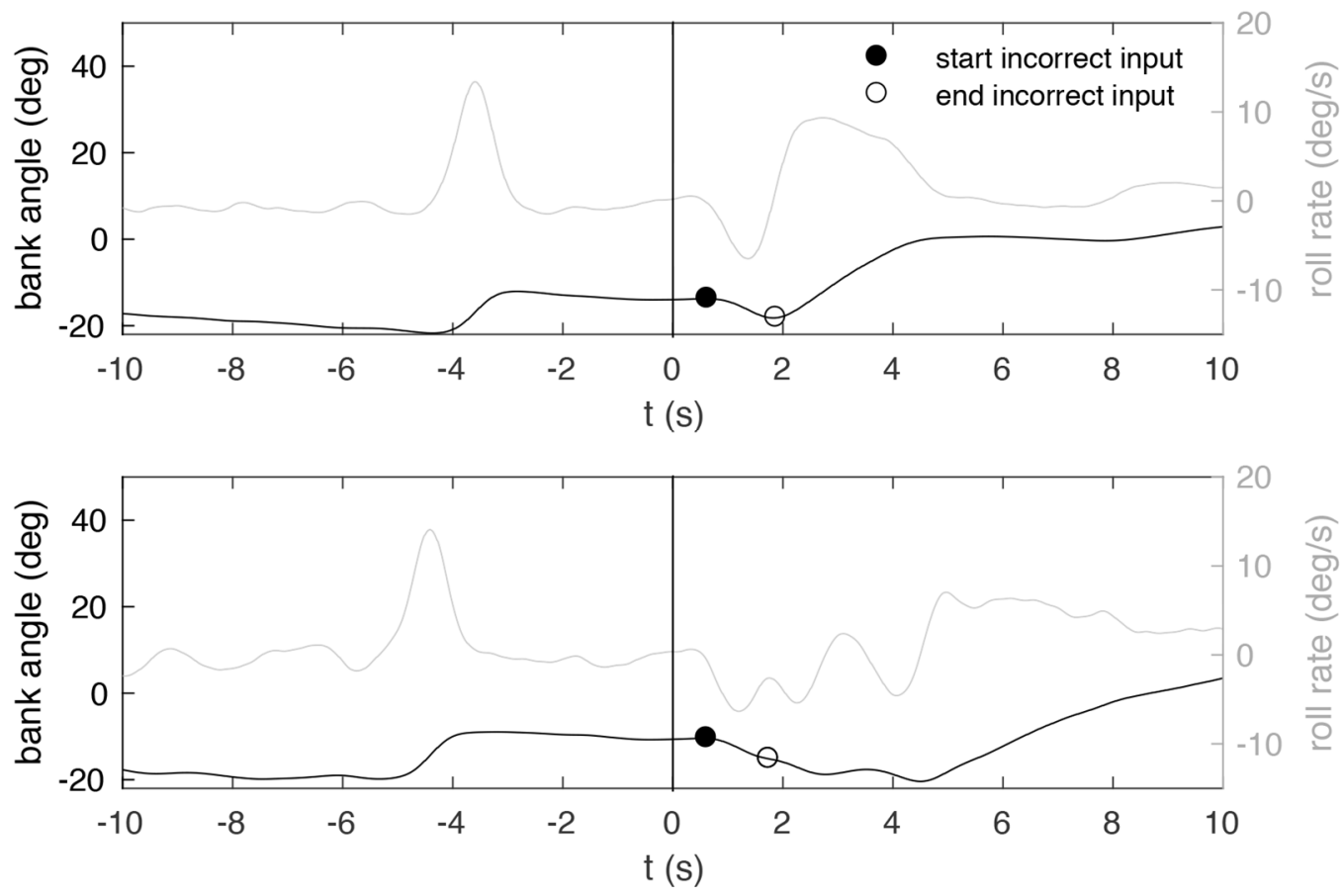

Figure 4. Two examples of roll reversal errors in the Leans-opposite condition. The plotted data represents the low-pass filtered (integrated) IMU data.

\subsection{Outcomes}

The mean (and standard deviation) of performance outcomes and run characteristics are presented in Table 2. For four participants, the video data were lost. For one participant, this was the case for the Leans-opposite and Leans-level condition only. This resulted in missing cases for the error duration, the reaction times and the blindfolding duration. Participants in the video recordings always looked at the AI instead of outside when removing the blindfold. One participant was excluded from the analysis due to prematurely removing the blindfold in a mismatching condition, which gave the participant insight into the maneuvers flown. A new participant was recruited instead.

Table 2. The means and standard deviations (SD) of performance variables and the run characteristics.

\begin{tabular}{|c|c|c|c|c|c|c|c|c|}
\hline & \multicolumn{2}{|c|}{ Matching } & \multicolumn{2}{|c|}{ No-leans } & \multicolumn{2}{|c|}{ Leans-opposite } & \multicolumn{2}{|c|}{ Leans-level } \\
\hline & Mean $(S D)$ & $\mathrm{N}$ & Mean $(S D)$ & $\mathrm{N}$ & Mean $(S D)$ & $\mathrm{N}$ & Mean $(S D)$ & $\mathrm{N}$ \\
\hline Error rate (\%) & $5.0(19.0)$ & 40 & $23.0(\mathrm{~N} / \mathrm{A})$ & 40 & $58.0(\mathrm{~N} / \mathrm{A})$ & 40 & $63.0(\mathrm{~N} / \mathrm{A})$ & 40 \\
\hline $\begin{array}{l}\text { Error } \\
\text { duration (s) }\end{array}$ & $.70(.11)$ & 2 & $.88(.63)$ & 8 & $.91(.76)$ & 19 & $.76(.52)$ & 24 \\
\hline Reaction time & $.50(.39)$ & 34 & $.77(.50)$ & 28 & $.67(.23)$ & 16 & $\mathrm{~N} / \mathrm{A}$ & $\mathrm{N} / \mathrm{A}$ \\
\hline
\end{tabular}




\begin{tabular}{lcccccccc}
$\begin{array}{l}\text { Reaction time } \\
\text { incorrect (s) }\end{array}$ & $.40(.21)$ & 2 & $.65(.22)$ & 8 & $.39(.34)$ & 19 & $.38(.42)$ & 25 \\
$\begin{array}{l}\text { Blindfolding } \\
\text { duration (s) }\end{array}$ & $27.0(3.0)$ & 36 & $31.2(8.0)$ & 36 & $34.7(6.6)$ & 35 & $33.4(5.1)$ & 35 \\
$\begin{array}{l}\text { Fast roll cue } \\
\text { duration (s) }\end{array}$ & $2.1(.38)$ & 40 & N/A & N/A & $1.5(.32)$ & 40 & $2.0(.33)$ & 40 \\
\hline
\end{tabular}

\subsubsection{Error rate}

The error rates are also graphically shown in Figure 5 . There was a significant main effect of Condition on error rate, $Q(2,38)=14.25, p=.001$. Significantly more (2.7 times as many) RREs were made in the Leans-opposite condition than in the No-leans condition, $p=.001$. There were also significantly more errors in the Leans-level condition than in the No-leans condition, $p=.002$. In contrast to our hypothesis, however, there was no significant difference between the Leansopposite and Leans-level condition, $p=.832$. All erroneous responses in the LeansLevel condition were towards the opposite site of the fast roll cue.

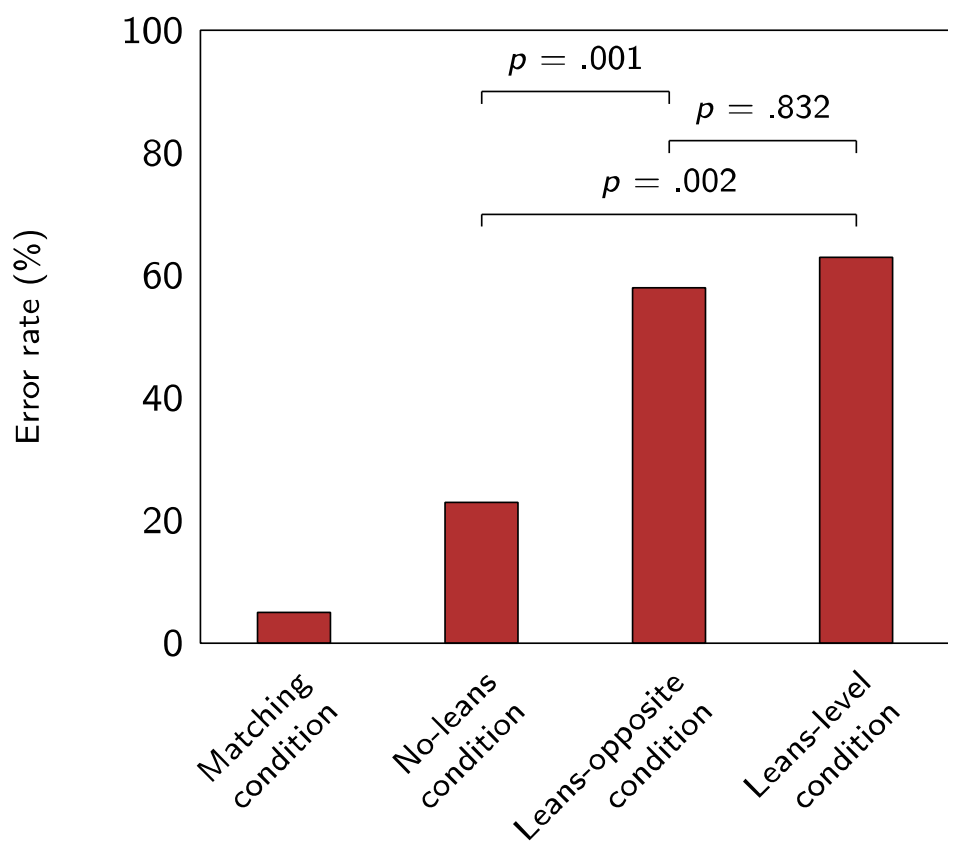

Figure 5. The mean error rates in the Matching condition (practice) and in the three test conditions.

\subsubsection{Error duration}

Scatterplots of the error durations are shown in Figure 6. There was a significant effect, $F(2,2)=25.27, p=.038$. Post-hoc analyses revealed that errors lasted significantly longer in the Leans-opposite condition than in the No-leans condition, $t(1,5)=3.19, \Delta=.53 \mathrm{~s}, p=.024$. 


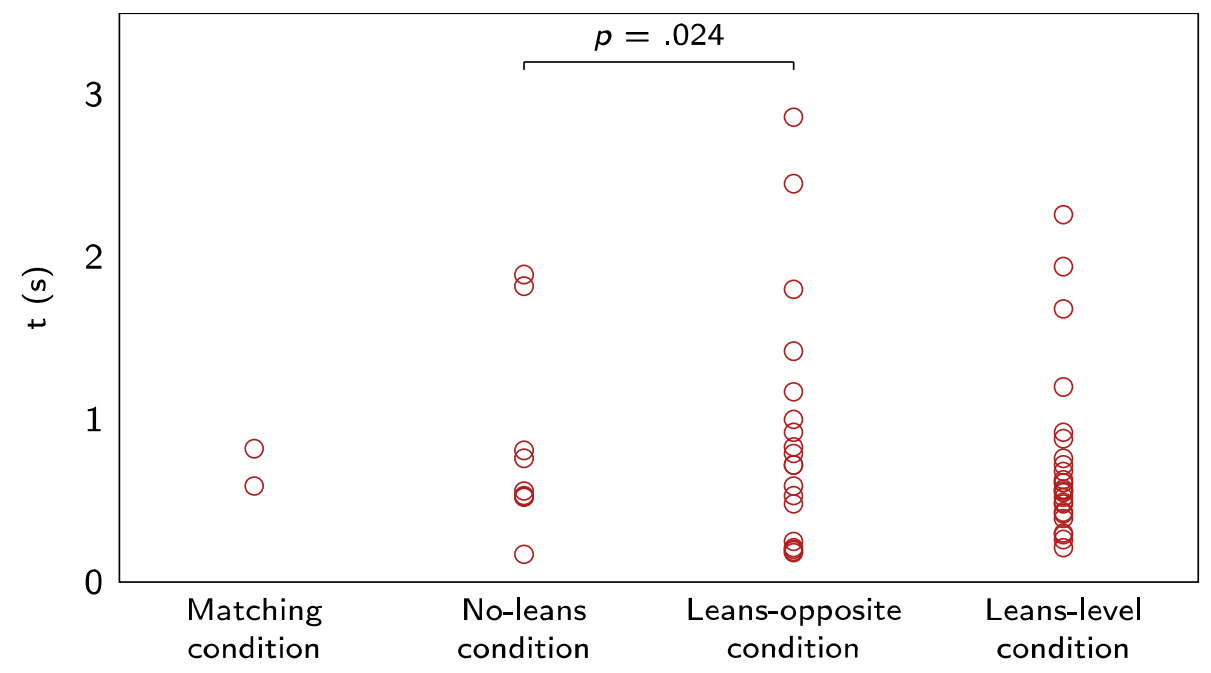

Figure 6. Scatterplots of the error durations.

\subsubsection{Reaction time}

Scatterplots of the reaction times are shown in Figure 7. There was no difference between erroneous and correct responses in the No-leans condition, $t(1,35)=.57$, $p=.574$, but there was in the Leans-opposite condition, $t(1,33)=2.78, p=.009$. In this condition, the reaction times of errors were $.28 \mathrm{~s}$ shorter than those of the correct responses.

When comparing the reaction time of correct responses between the conditions (No-leans and Leans-opposite), there was no significant difference, $t(1,14)=.16, p=.879$.

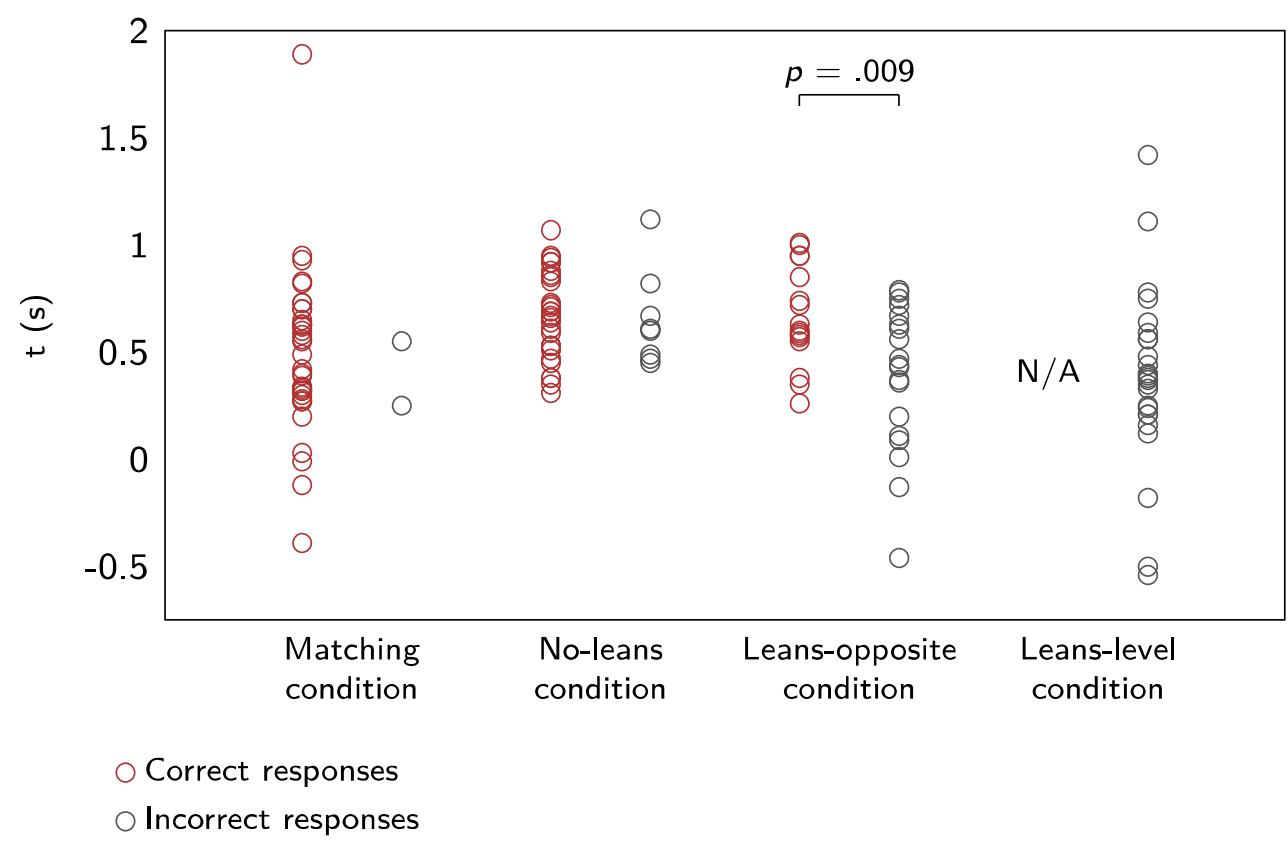


Figure 7. Scatterplots of the reaction times of the correct responses and incorrect responses.

\subsubsection{Learning effect}

The sequence of the conditions significantly predicted whether an error was made in the Leans-level condition only, $B=2.14, p=.006$. Participants were approximately twice as likely to make an error if the Leans-level condition was the first condition, compared to the last. There were no significant effects of the sequence of the conditions on error duration.

\subsubsection{Run similarity check}

Participants were blindfolded for a significantly longer time in the Leans-opposite condition than in the No-leans condition, $t(1,34)=2.47, p=.019, \Delta=3.4 \mathrm{~s}$. This difference is small compared to the average blindfolding time (i.e., ca. $30 \mathrm{~s}$ ). The duration of the fast roll cue was significantly longer in the Leans-level condition than in the Leans-opposite condition, $t(1,39)=7.37, p<.001, \Delta=.51 \mathrm{~s}$.

\subsubsection{Subjective variables}

Two missing cases resulted from forgetting to question the participant. Four out of the remaining eighteen questioned participants (22\%) indicated that they perceived a bank angle at the end of the blindfold phase during the No-leans condition. This perceived bank angle was in the direction of the actual bank angle in two cases, and into the opposite direction in two other cases.

\section{Discussion}

The results showed that misleading motion cues of the aircraft bank angle had a strong influence on the participants' control inputs. Both conditions involving leans cues (Leans-level and Leans-opposite) showed error rates of about $60 \%$, that is, 2.7 times higher than in the No-leans condition (23\%). The RRE rate in the No-leans condition was similar to those found in previous in-flight experiments with non-pilots (21.9-23.6 \%; Roscoe \& Williges, 1975; Ince, Williges \& Roscoe, 1975). Thus, the current results indicate that the likelihood of making an RRE greatly increases when one has a false sensation of the bank angle.

We expected the highest RRE rate in the Leans-opposite condition, as this condition presents the possibility of making interpretation errors (i.e., horizon control reversals). However, contrary to our hypothesis, the RRE rates were not significantly higher in the Leans-opposite condition than in the Leans-level condition. Thus, there was no evidence of misinterpretations, and the errors in both leans conditions could instead have been caused by participants responding too quickly and neglecting the AI. Indeed, reaction times of incorrect responses in the Leans-opposite condition were faster than correct responses. Compared to a similar (level) condition in a previous fixed-base study by Landman et al. (2018), the error rate in the in-flight Leans-level condition was much higher $(63 \%$ compared to $30 \%$ ). This suggests that motion cues had a stronger influence on 
the responses than a manipulation of the expectation with a fixed-base flying task. There was also no significant difference between the conditions in error duration and reaction time of correct responses. Thus, these supplementary measures besides RREs showed no additional evidence that participants had more difficulty in responding to the AI or in correcting incorrect responses when leans cues were present.

Caution should be taken when extrapolating our findings from non-pilots to pilots. Pilots are likely less susceptible to misleading motion cues and misinterpretations of the AI due to their flying experience and knowledge. However, previous in-flight experiments found that pilots are not impervious to issues with reading the AI, as they made RREs at rates of 1.5-3.1\% (Beringer, Williges, Roscoe, 1975; Hasbrook \& Rasmussen, 1973). The outcomes of the current study hint that also pilots may produce higher error rates when they are spatially disoriented or suffering from surprise.

Another issue to take into account in the interpretation of the results, is the variation in the manually flown maneuvers. The fast roll cue in the Leans-level condition lasted longer than in the Leans-opposite condition due to standardization of the start of this cue (i.e., $20^{\circ}$ bank). Based on verbal reports by the participants, it seems that there were sometimes inadvertent leans sensations present in the No-leans condition. Some participants indicated that they were surprised by the bank angle in the No-leans condition, which may have affected their response. Finally, the current experiment focused on responses during static bank angles, while it has been argued that interpretational issues are worse during roll motions (Roscoe, 1968).

For future experiments on this topic, the following lessons were learned with regard to the methodology. First, it may be wise to include at least one run with level flight in the practice runs, to prevent that participants presume that they always need to give an input. Second, although test flights indicated that the outside view wasn't noticeable when focusing on the AI, the information presented to participants could be more tightly controlled by covering the side window or by using training glasses that prevent outside vision (i.e. 'foggles').

\section{Conclusions}

The results of this study show that misleading motion cues induce incorrect expectations, which in turn cause RREs. The comparison between different leans conditions indicated that this effect could be attributed to participants responding too quickly based on their assumption of the bank angle, while neglecting the AI.

Although the study was performed with non-pilots, the outcomes suggest several aspects are likely important to consider when training pilots or performing research on pilot control. The found effect of leans cues on expectation and control behavior underlines the importance of accurate motion cues for both training and research. Second, the effectiveness of a display system may be strongly diminished when the controller has mismatching expectations. It would therefore be wise to test, for instance, upset recovery display aides (e.g., Ewbank, Mumaw \& Snow, 2016) when mismatching expectations are present. The results also suggest that taking more time to 'look twice' before giving an input could be an effective countermeasure. 


\section{References}

Aircraft Accident Investigation Bureau, 2002. Final Report of the Aircraft Accident Investigation Bureau on the Accident to the Saab 340B Aircraft, Registration HB-AKK of Crossair Flight CRX 498 on 10 January 2000 Near Nassenwil/ZH. Retrieved from. https://www.sust.admin.ch/inhalte/AVberichte/1781_e.pdf.

Bauerschmidt, D.K., Roscoe, S.N., 1960. A comparative evaluation of a pursuit moving- airplane steering display. IRE Trans. Hum. Factors Electron. (2), 6266. https://doi. org/10.1109/THFE2.1960.4503277.

Belcastro, C.M., Foster, J.V., Shah, G.H., Gregory, I.M., Cox, D.E., Crider, D.A., et al., 2017. Aircraft loss of control problem analysis and research toward a holistic solu- tion. J. Guid. Control Dyn. 40 (4), 733-775. https://doi.org/10.2514/1.G002815.

Beringer, D.B., Williges, R.C., Roscoe, S.N., 1975. The transition of experienced pilots to a frequency-separated aircraft attitude display. Hum. Factors 17 (4), 401-414. https:// doi.org/10.1177/001872087501700411.

Bureau d'Enquêtes et d'Analyses pour la Sécurité de l'Aviation Civile, 2012. Final report on the accident on 1st June 2009 to the Airbus A330-203, registered FGZCP, oper- ated by Air France, Flight AF 447 Rio de Janeiro-Paris. Le Bourget, France.

Cameroon Civil Aviation Authority, 2010. Technical Investigation into the Accident of the B737-800 Registration 5y-Kya Operated by Kenya Airways that Occurred on the 5th of May 2007 in Douala. Retrieved from. https://reports.aviation-safety.net/2007/ 20070505-0_B738_5Y-KYA.pdf.

Ewbank, C.E., Mumaw, R.J., Snow, M.P., 2016. Development of the enhanced bank angle warning. IEEE/AIAA 35th Digital Avionics Systems Conference (DASC) 1-9.

Gillingham, K.K., 1992. The spatial disorientation problem in the United States Air Force. J. Vestib. Res. 2 (4), 297-306.

Gundry, A.J., 1978. Experiments on the detection of roll motion. Aviat. Space Environ. Med. 49, 657-664.

Hasbrook, A.H., Rasmussen, P.G., 1973. In-flight Performance of Civilian Pilots Using Moving-Aircraft and Moving-Horizon Attitude Indicators. Federal Aviation Administration. Civil Aeromedical Institute, Oklahoma City, OK.

Holmes, S.R., Bunting, A., Brown, D.L., Hiatt, K.L., Braithwaite, M.G., Harrigan, M.J., 2003. Survey of spatial disorientation in military pilots and navigators. Aviat. Space Environ. Med. 74 (9), 957-965.

Ince, F., Williges, R.C., Roscoe, S.N., 1975. Aircraft simulator motion and the order of merit of flight attitude and steering guidance displays. Hum. Factors 17 (4), 388-400. https://doi.org/10.1177/001872087501700410.

Johnson, S.L., Roscoe, S.N., 1972. What moves, the airplane or the world? Hum. Factors 14 (2), 107-129. https://doi.org/10.1177/001872087201400201.

Landman, A., Groen, E.L., van Paassen, M.M., Bronkhorst, A.W., Mulder, M., 2018. Incongruent Expectation Causes Misinterpretation of the Attitude Indicator in Non- pilots: a Fixed-Base Simulator Experiment. Manuscript submitted for publication. 
Maloney, L.T., Zhang, H., 2010. Decision-theoretic models of visual perception and ac- tion. Vis. Res. 50 (23), 2362-2374.

Müller, S., Sadovitch, V., Manzey, D., 2018. Attitude indicator design in primary flight display: revisiting an old issue with current technology. Int. J. Aerospace Psychol. 1-16. https://doi.org/10.1080/24721840.2018.1486714.

Navathe, P.D., Singh, B., 1994. Prevalence of spatial disorientation in Indian Air Force aircrew. Aviat. Space Environ. Med. 65 (12), 1082-1085.

Previc, F.H., Ercoline, W.R., 1999. The outside-in attitude display concept revisited. Int. J. Aviat. Psychol. 9 (4), 377-401. https://doi.org/10.1207/s15327108ijap0904_5.

Roscoe, S.N., Williges, R.C., 1975. Motion relationships in aircraft attitude and guidance displays: a flight experiment. Hum. Factors 17 (4), 374-387. https://doi.org/10.1177/001872087501700409.

Roscoe, S.N., 1968. Airborne displays for flight and navigation. Hum. Factors 10 (4), 321-332.

Roscoe, S.N., 2004. Moving horizons, control reversals, and graveyard spirals. Ergon. Des 12 (4), 15-19. https://doi.org/10.1177/106480460401200405.

Singer, G., Dekker, S., 2002. The effect of the roll index (sky pointer) on roll reversal errors. Hum. Factors Aerosp. Saf. 2 (1), 33-43.

Wickens, C.D., 2003. Aviation displays. In: Tsang, P.S., Vidulich, M.A. (Eds.), Principles and Practice of Aviation Psychology. Lawrence Erlbaum, Mahwah, NJ, pp. 147-200. 
2019-06-26

In-flight spatial disorientation induces roll reversal errors when using the attitude indicator

\author{
Landman, Annemarie
}

Elsevier

Landman A, Davies S, Groen EL, et al., (2019) In-flight spatial disorientation induces roll reversal errors when using the attitude indicator. Applied Ergonomics, Volume 81, November 2019, Article number 102905

https://doi.org/10.1016/j.apergo.2019.102905

Downloaded from Cranfield Library Services E-Repository 